$$
\begin{aligned}
& \text { تأثير نسبة التدوير والحمل العضوي وحمل المواد الصلبة العالقة على كفاعة المرشح } \\
& \text { الحيوي ذي الوسط البلاستيكي }
\end{aligned}
$$

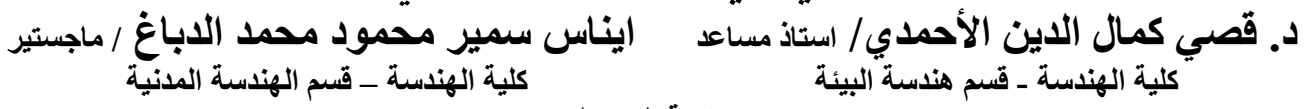

$$
\begin{aligned}
& \text { جامعة الموصل } \\
& \text { الخلاصة الخدة الموصل }
\end{aligned}
$$

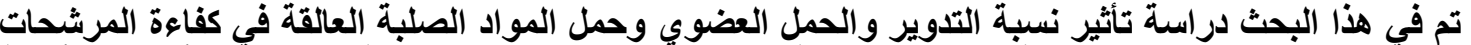

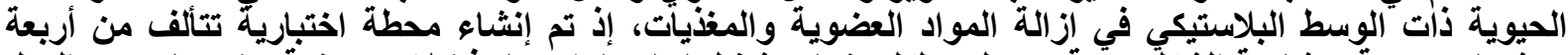

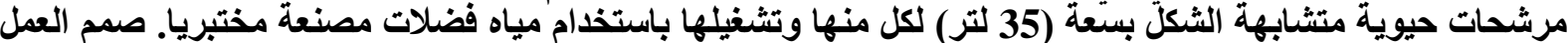

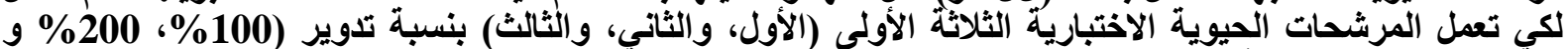

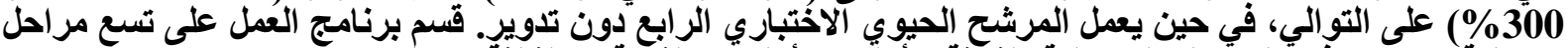

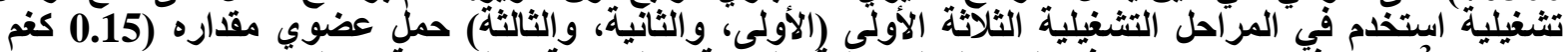

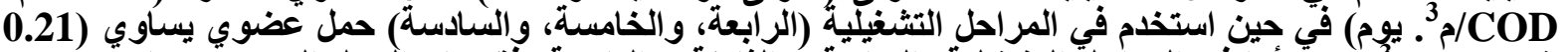
كغم كفم كغم

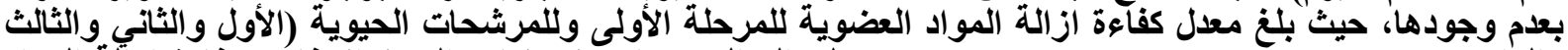

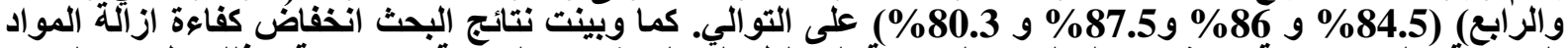

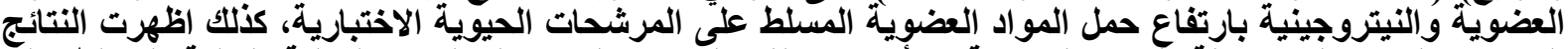

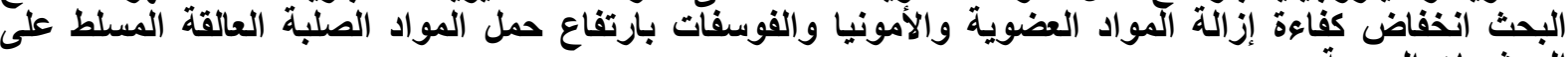

Keywords: Biological treatment, Trickling filter, Recirculation ratio, TSS., Aerobic

\title{
Effect of Recirculation Ratio, Organic Loading and Suspended Solids Loading on the Efficiency of the Trickling Filters With Plastic Media
}

\author{
Dr. K. K. Al-Ahmady/ Ass. Professor \\ Environmental Eng. \\ E. S. M. AL-Dabag \\ Dept. Civil Dept. \\ College of Engineering, University of Mosul
}

\section{Abstract}

In this research, an experimental laboratory plant was constructed in order to evaluate the effect of recirculation ratio, organic loading and suspended solids loading on the removal efficiency of trickling filter with plastic media. The plant consisted of four biological trickling filter which were similar in shape, each with a volume equal to (35 liters). Synthetic wastewater was used to operate the plant. To study the impact of recirculation ratio on the system, three of these plants (first, second and third) were operated on recirculation ratio of $(100 \%, 200 \%$ and $300 \%)$ respectively, whereas the fourth operated without recirculation. To study the effect of increase organic loading, the study program was divided into nine stages, in the three continuation following stages the organic loading rate was steady then increasing in the three suffix continuation following stages thus until ultimate ninth stage, beginning with $(1.5 \mathrm{~kg}$ $\mathrm{COD} / \mathrm{m}^{3}$.day) then $\left(2.1 \mathrm{~kg} \mathrm{COD} / \mathrm{m}^{3}\right.$.day $)$ and up to $\left(2.7 \mathrm{~kg} \mathrm{COD} / \mathrm{m}^{3}\right.$.day $)$. The results of the study revealed that; the removal efficiency of the biological trickling filter increase when the recirculation operation was exist, and the efficiency increased when increase recirculation ratio, so the average efficiency of first stage removal of organic loading was in the trickling filters (first, second, third and fourth ) $(84.5 \%, 86.3 \%, 87.5 \%, 80 \%$ ) respectively. The results also showed that; increasing organic and suspended solid loading decreases removal efficiency of organic matter, ammonia and phosphate. 


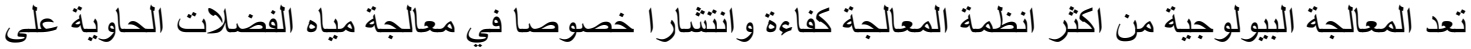

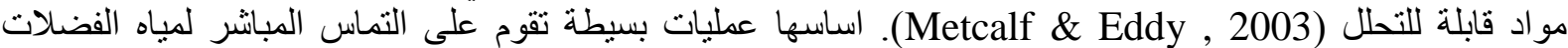

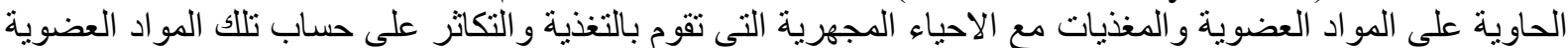
و المغذيات وبالتالي تنقية مياه الفضلات (Kharrufa, 1985). ومن هذه الانظمة المرشح الحئية الحيوي (Trickling Filter).

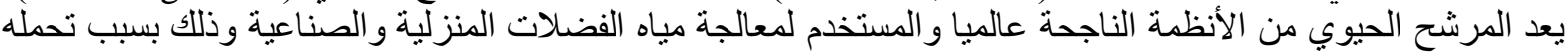

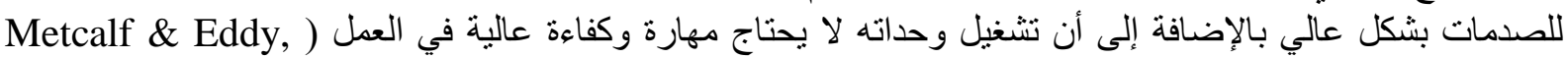

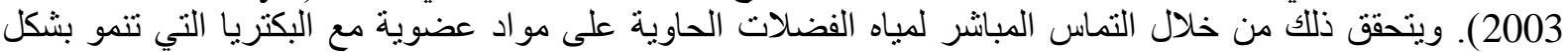

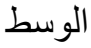
على

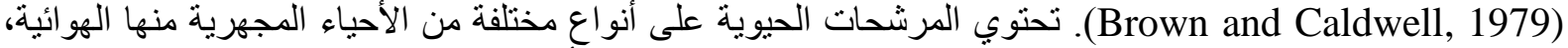

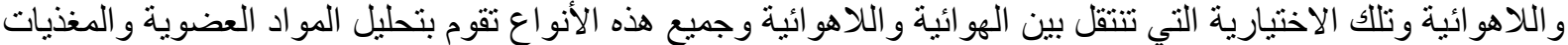

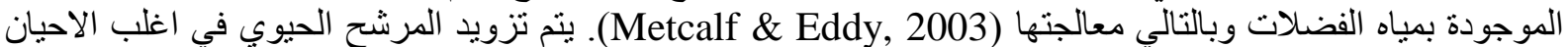
بعملية تدوير (Recirculation) وذلك لزيادة فترة تماس البكتريا بمياه الفضلات اضافة لزيادة الاوكسجين اللازم لعملية الإلية الفضلات الفيلات وازالة الة

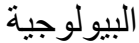
الاكسدة (Metcalf \& Eddy, 2003). تستخدم المرشحات الحيوية اوساط (Media) مثل الحجر أو الحصى أو القطع البلاستيكية

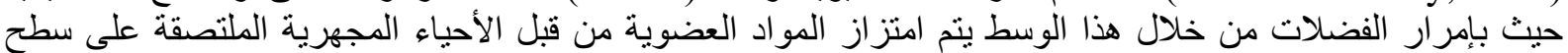

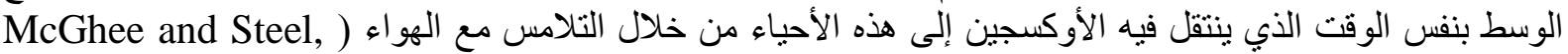

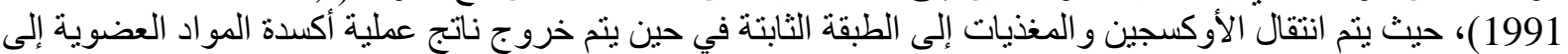

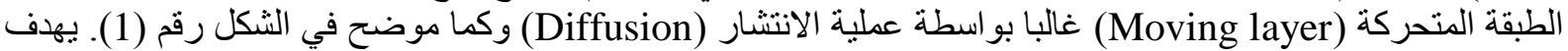

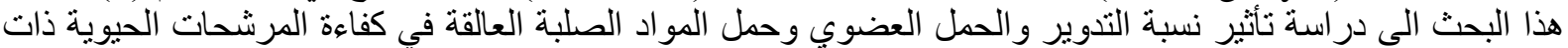

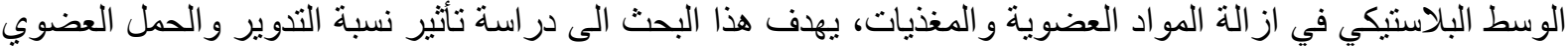

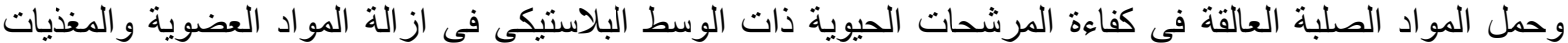
وضمن ظروف تشغيلية مختلفة

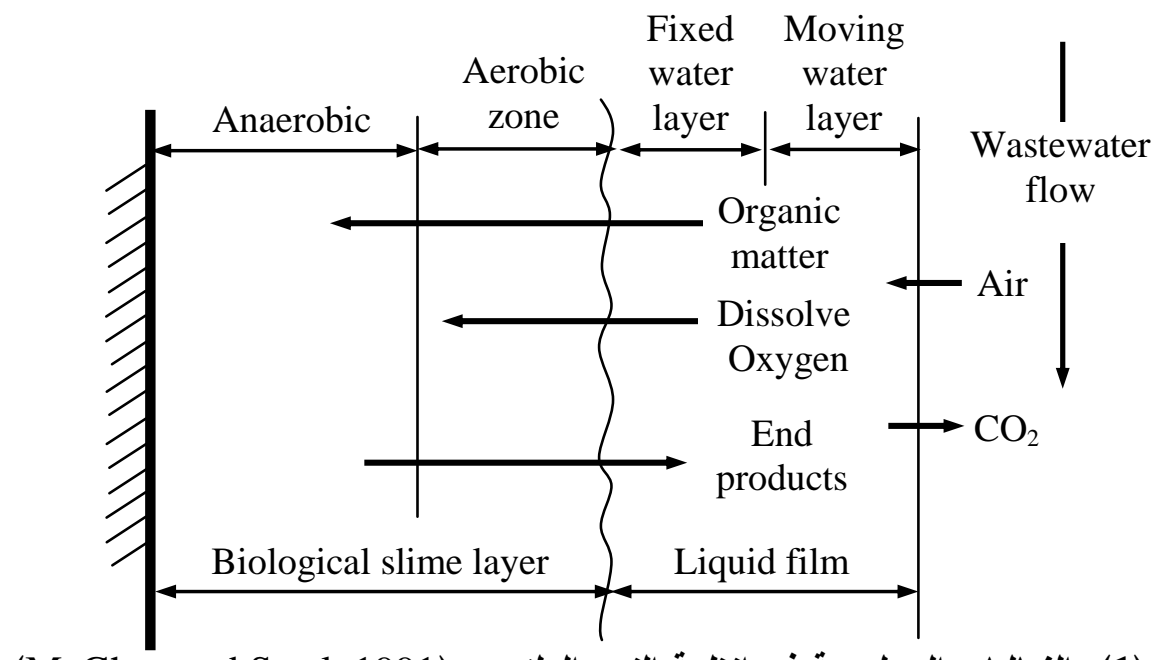

الثكل (1) الفعاليات البيولوجية في انظمة النمو الملتصق (McGhee and Steel, 1991)

الاراسات السابقة قام الباحث (Maheesan et al, 2011) بمعالجة مياه فضلات بلدية وذللك بإنشاء محطة اختبارية تتكون من مرشح حيوي ذو وسط بلاستيكي وبنظام تشغيل متقطع (Intermittent Operation System). اثبتت النتائج قابلية

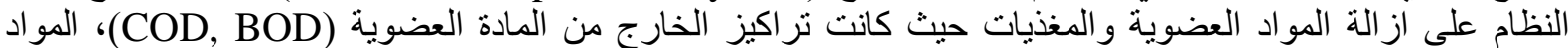

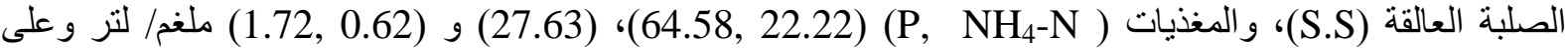

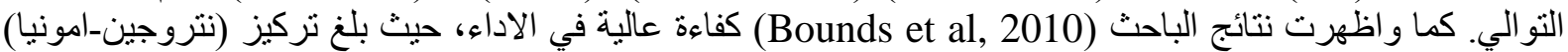

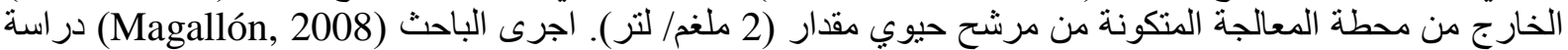
على محطة معالجة مياه فضلات مدنية تحنوي مرشح حيوي ذو ذوسط وسط بلاستيكي ونسبة تدوير (100\%). استنتج الباحث ان 
كفاءة از الة المو اد العضوية كانت تتراوح ما بين (75 - 85 \% \%). كما وقد اجرى الباحث (Khan, et al; 2005) دراسة باسة

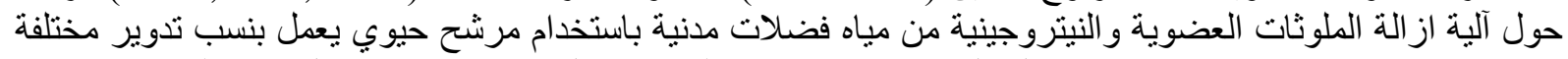

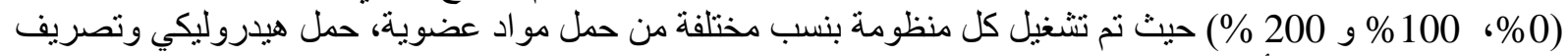

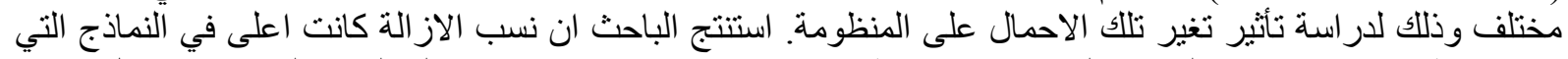

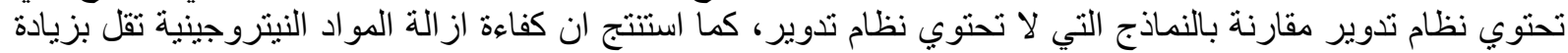

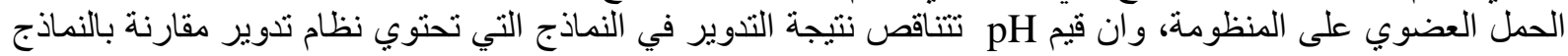
التي لا تحتوي نظام تدوير.

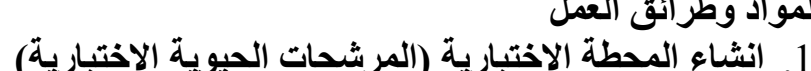

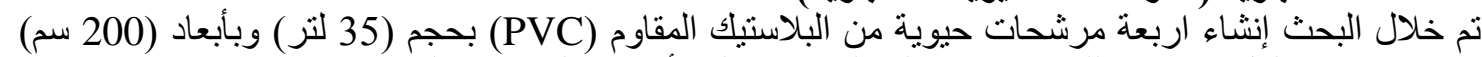

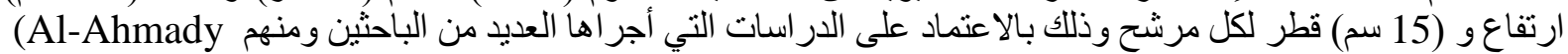
(Morton, 2001) gand Al-Rahmani, 2011)

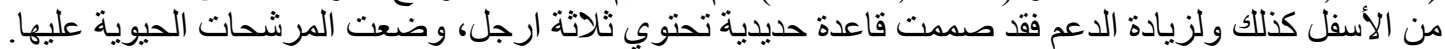

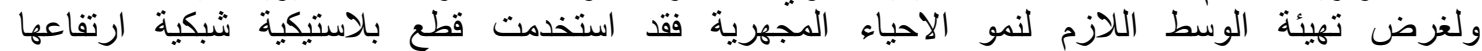

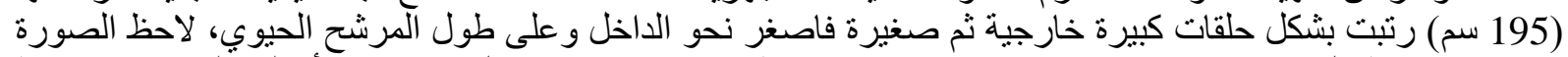

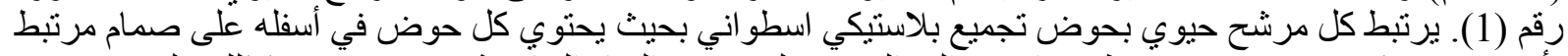

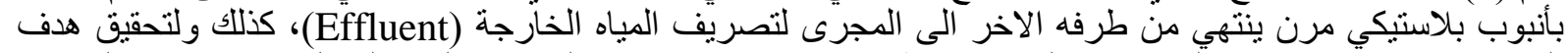

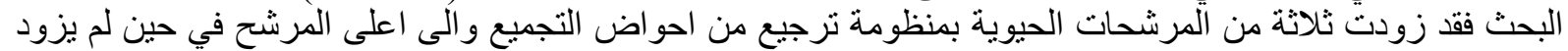

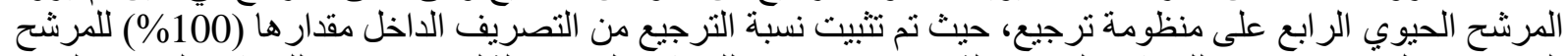

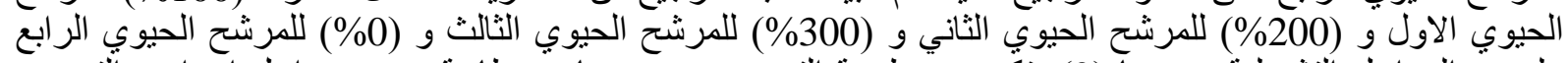

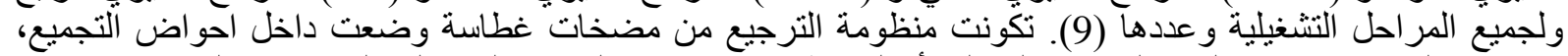

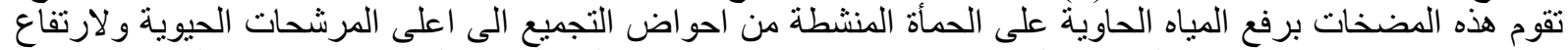

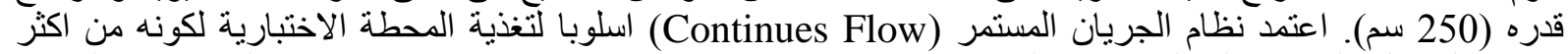

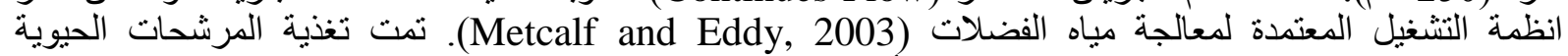

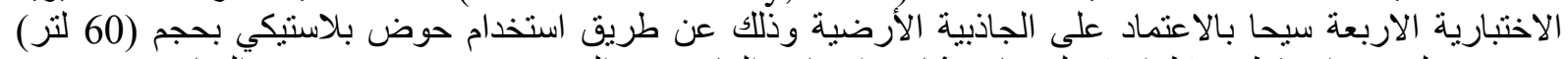

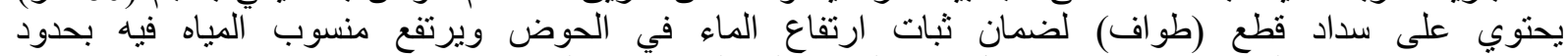

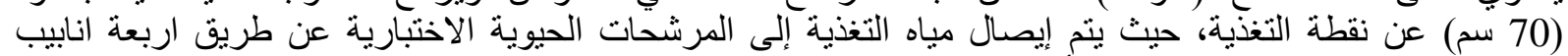

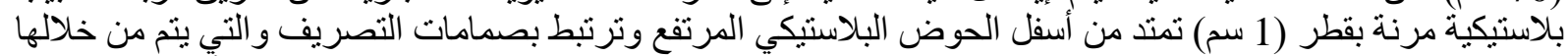

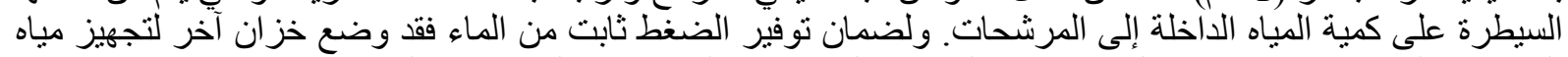

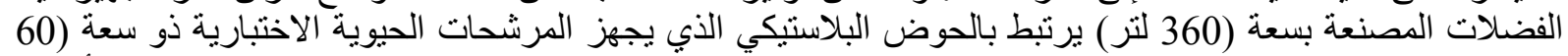

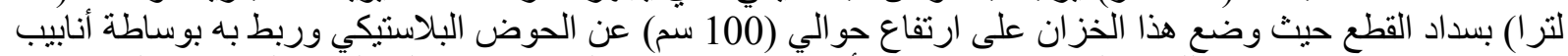

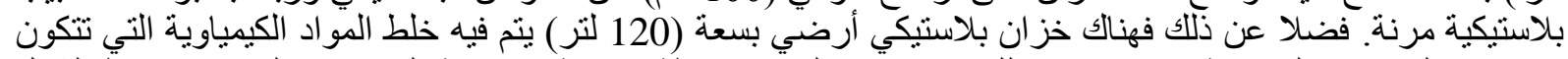

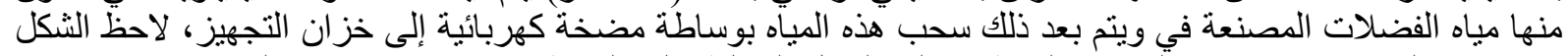

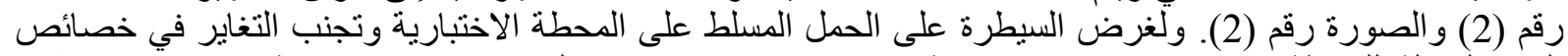

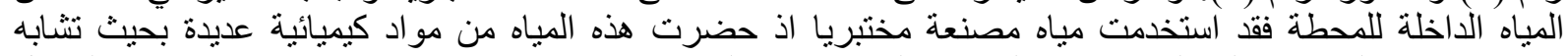

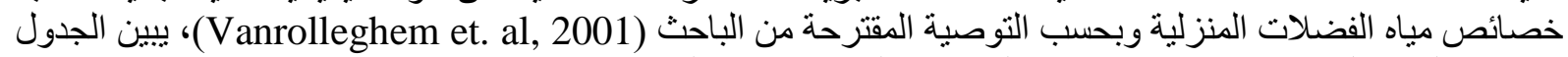
رقم (1) المو اد المستخدمة في صناعة مياه الفضلات الفنات المستخدمة في البحث.

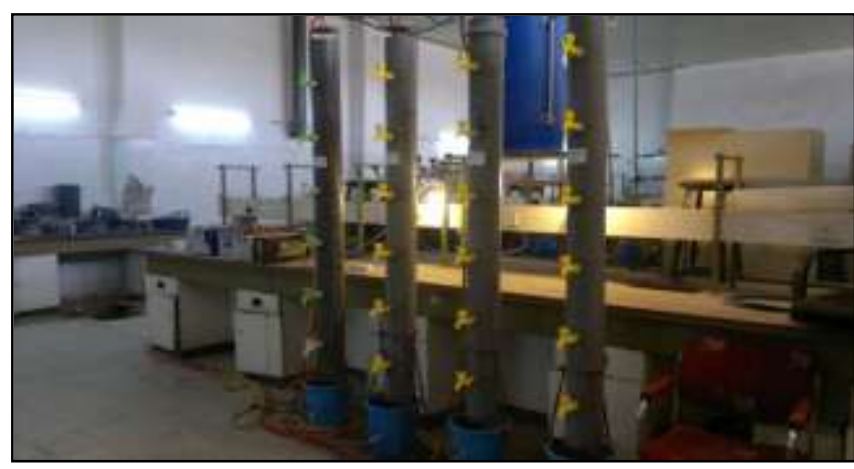

الصورة (2): المرشحات الحيوية المختبرية المستخدمة في البحث

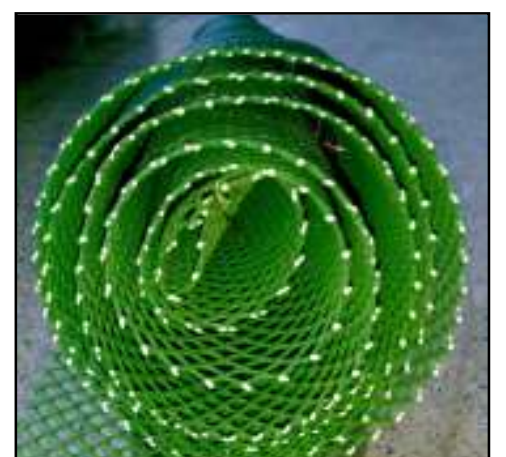

الصورة (1): الوسط البلاستيكي المستخدم 


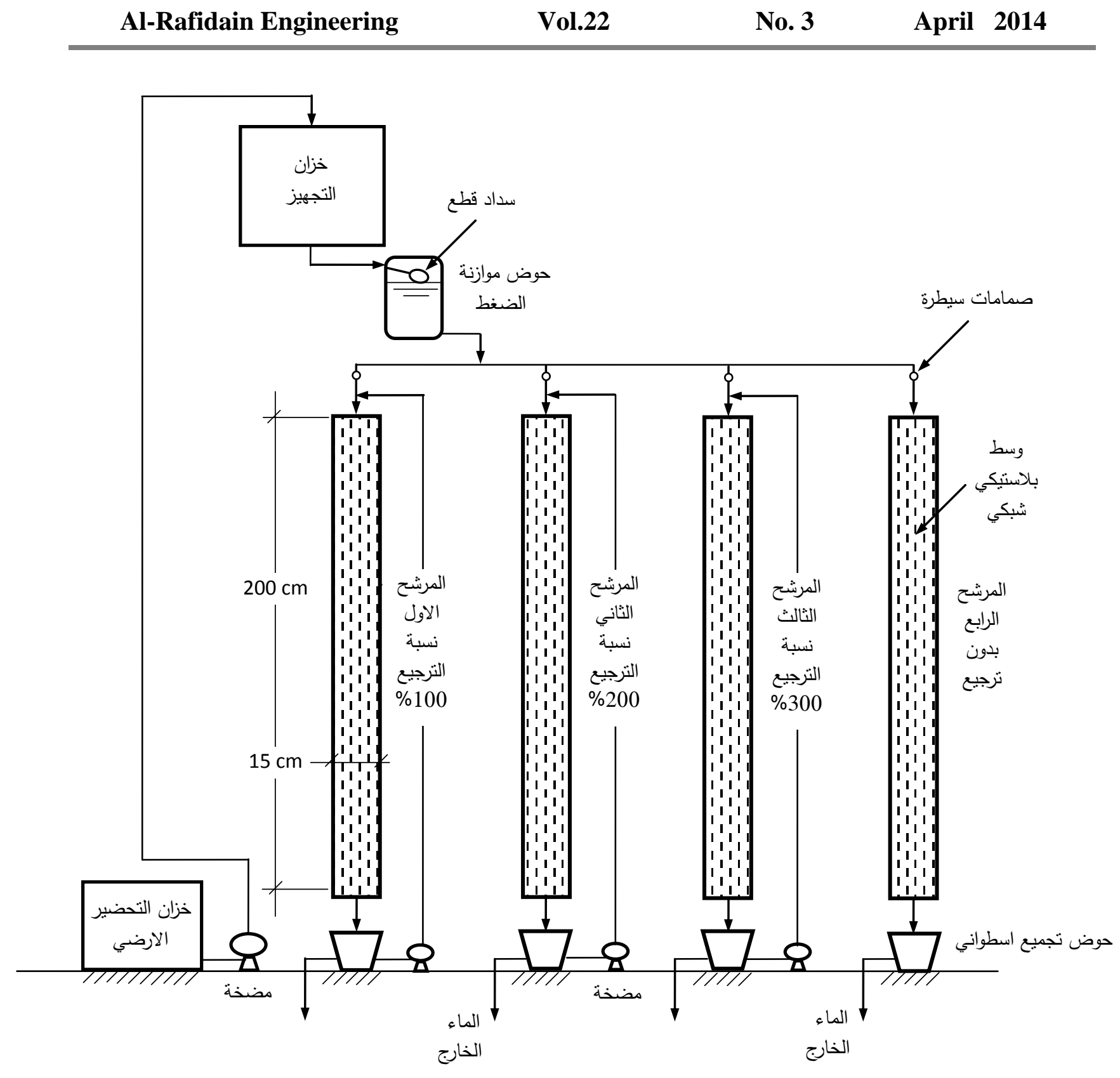

الثكل (2): اسلوب ربط المحطة الاختبارية المستخدمة في البحث

الجدول رقم (1) المواد المستخدمة في صناعة مياه الفضلات الثبيهة بمياه الفضلات المنزلية

\begin{tabular}{|c|c|c|}
\hline الرمز الكيميائي & اسم المادة & التسلسل \\
\hline $\mathrm{NH}_{4} \mathrm{CL}$ & كلوريد الأمونيوم & 1 \\
\hline- & ببتون & 2 \\
\hline $\mathrm{KH}_{2} \mathrm{PO}_{4}$ & فوسفات البوتاسيو ثثنائية الهيدروجين & 3 \\
\hline $\mathrm{C}_{6} \mathrm{H}_{12} \mathrm{O}_{6}$ & النشا & 4 \\
\hline- & الحليب & 5 \\
\hline $\mathrm{K}_{2} \mathrm{HPO}_{4}$ & فوسفات البوتاسيوم احادية الهيدروجين اللامائية & 6 \\
\hline $\mathrm{MgSO}_{4} \cdot 7 \mathrm{H}_{2} \mathrm{O}$ & كبريتات المغنيسيوم & 7 \\
\hline $\mathrm{CN}_{2} \mathrm{H}_{4} \mathrm{O}$ & 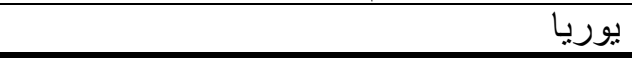 & 8 \\
\hline
\end{tabular}


2. المراحل والظروف التشغيلية (Operational Stages)

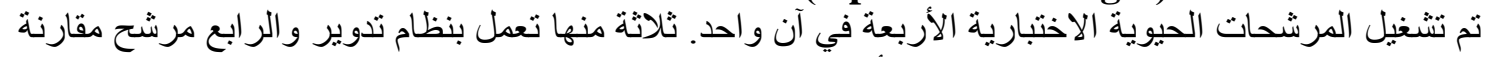
(Reference trickling filter)

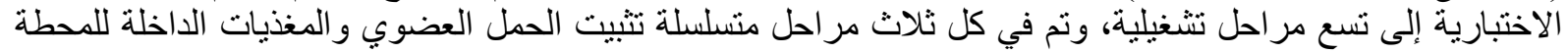

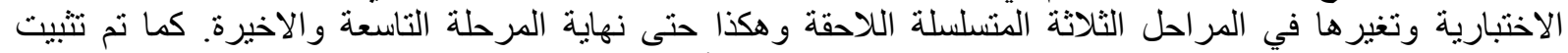

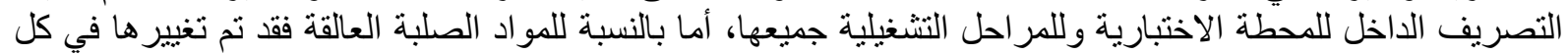

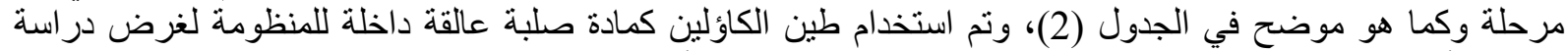

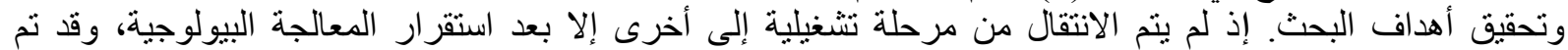

الاستدلال على حالة الاستقر ار من خلال ثبوت كفاءة المعالجة (Metcalf and Eddy, 2003).

جدول (2) المراحل التثغيلية للمحطة الاختبارية

\begin{tabular}{|c|c|c|c|c|c|c|c|}
\hline الصلبة العالقة & الصلبة العالقة & (كفم/م.3. الفونوم) & النيتروجينية المواد & العضوي (كفم) & (التصريف) & $\begin{array}{l}\text { التدوير } \\
\text { (\%) }\end{array}$ & الاختبارية \\
\hline \multicolumn{8}{|c|}{ المرحلة الأولى } \\
\hline \multirow{4}{*}{58.3} & \multirow{4}{*}{0.15} & \multirow{4}{*}{9.42} & \multirow{4}{*}{47.12} & \multirow{4}{*}{1.5} & \multirow{4}{*}{0.09} & 100 & المرشح الأول \\
\hline & & & & & & 200 & المرشح الثاني \\
\hline & & & & & & 300 & المرشح الثالثة \\
\hline & & & & & & 0 & المرشح الرابع \\
\hline \multicolumn{8}{|c|}{ المرحلة الثانية } \\
\hline \multirow{4}{*}{97.2} & \multirow{4}{*}{0.25} & \multirow{4}{*}{9.42} & \multirow{4}{*}{47.12} & \multirow{4}{*}{1.5} & \multirow{4}{*}{0.09} & 100 & المرشح الأول \\
\hline & & & & & & 200 & المرشح الثانى \\
\hline & & & & & & 300 & المرشح الثالث \\
\hline & & & & & & 0 & المرشح الرابع \\
\hline \multicolumn{8}{|c|}{ المرحلة الثالثة } \\
\hline \multirow{4}{*}{136.1} & \multirow{4}{*}{0.35} & \multirow{4}{*}{9.42} & \multirow{4}{*}{47.12} & \multirow{4}{*}{1.5} & \multirow{4}{*}{0.09} & 100 & المرشح الأول \\
\hline & & & & & & 200 & المرشح الثاني \\
\hline & & & & & & 300 & المرشح الثالث \\
\hline & & & & & & 0 & المرشح الرابع \\
\hline \multicolumn{8}{|c|}{ المرحلة الرابعة } \\
\hline \multirow{4}{*}{58.3} & \multirow{4}{*}{0.15} & \multirow{4}{*}{13.18} & \multirow{4}{*}{65.96} & \multirow{4}{*}{2.1} & \multirow{4}{*}{0.09} & 100 & المرشح الأول \\
\hline & & & & & & 200 & المرشح الثانى \\
\hline & & & & & & 300 & المرشح الثالث: \\
\hline & & & & & & 0 & المرشح الرابع \\
\hline & & & لـة الخامسة & & & & \\
\hline & & & & & & 100 & المرشح الأول \\
\hline 070 & 005 & 11 & 60 & & 000 & 200 & المرشح الثانى \\
\hline 97.2 & 0.25 & 13.18 & 65.96 & 2.1 & 0.09 & 300 & المرشح الثالثة \\
\hline & & & & & & 0 & المرشح الرابع \\
\hline & & & ل لية السادسة & & & & \\
\hline & & & & & & 100 & المرشح الأول \\
\hline 1361 & 035 & 1318 & 6506 & 21 & 000 & 200 & المرشح الثاني \\
\hline 150.1 & 0.33 & 13.18 & 05.96 & 2.1 & 0.09 & 300 & المرشح الثالث \\
\hline & & & & & & 0 & المرشح الرابع \\
\hline & & & طلة السابعة & & & & \\
\hline & & & & & & 100 & المرشح الأول \\
\hline 58.3 & 0.15 & 16.96 & 84.8 & 2.7 & 0.09 & 200 & المرشح الثاني \\
\hline & & & & & & 300 & المرشح الثالث \\
\hline
\end{tabular}




\begin{tabular}{|c|c|c|c|c|c|c|c|}
\hline & & & & & & 0 & المرشح الرابع \\
\hline \multicolumn{8}{|c|}{ المرحلة الثامنة } \\
\hline \multirow{4}{*}{97.2} & \multirow{4}{*}{0.25} & \multirow{4}{*}{16.96} & \multirow{4}{*}{84.8} & \multirow{4}{*}{2.7} & \multirow{4}{*}{0.09} & 100 & المرشح الأول \\
\hline & & & & & & 200 & المرشح الثاني \\
\hline & & & & & & 300 & المرشح الثالث \\
\hline & & & & & & 0 & المرشح الر ابع \\
\hline & & & التاسعقة & & & & \\
\hline \multirow{4}{*}{136.1} & \multirow{4}{*}{0.35} & \multirow{4}{*}{16.96} & \multirow{4}{*}{84.8} & \multirow{4}{*}{2.7} & \multirow{4}{*}{0.09} & 100 & المرشح الأول \\
\hline & & & & & & 200 & المرشح الثاني \\
\hline & & & & & & 300 & المرشح الثالث \\
\hline & & & & & & 0 & المرشح الرابع \\
\hline
\end{tabular}

النتائج والمناقثة

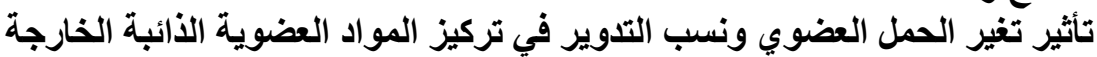

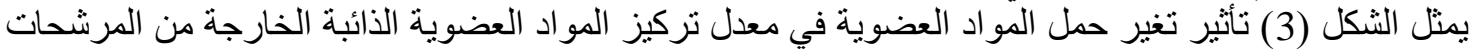

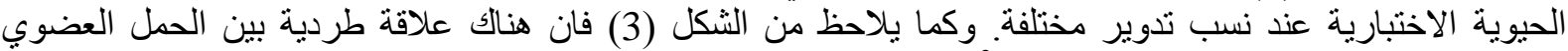

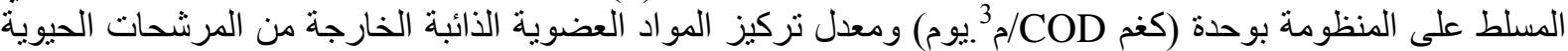

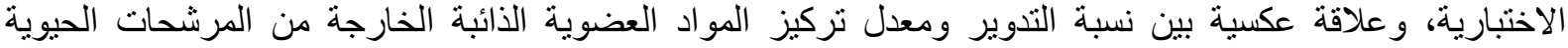

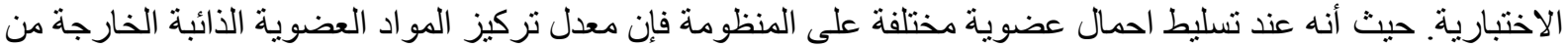

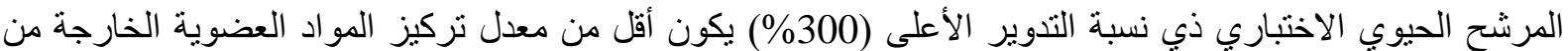

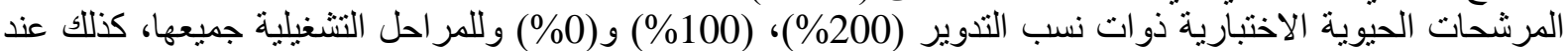
العضوي

(2.1 كغم/23. يوم) فإن معدل تركيز المادة العضوية الذائبة الخارجة من المرشح الحيوي الاختباري ذي نسبة التدوير

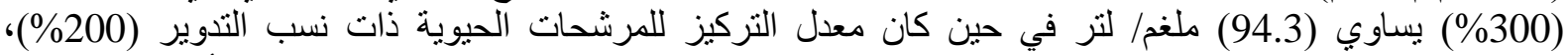

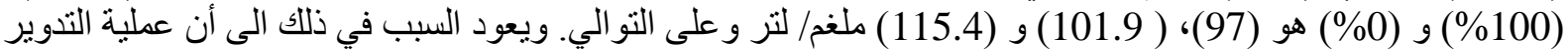

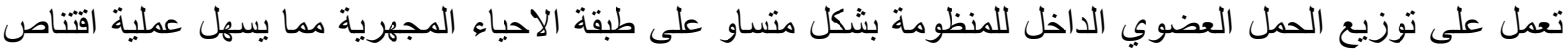

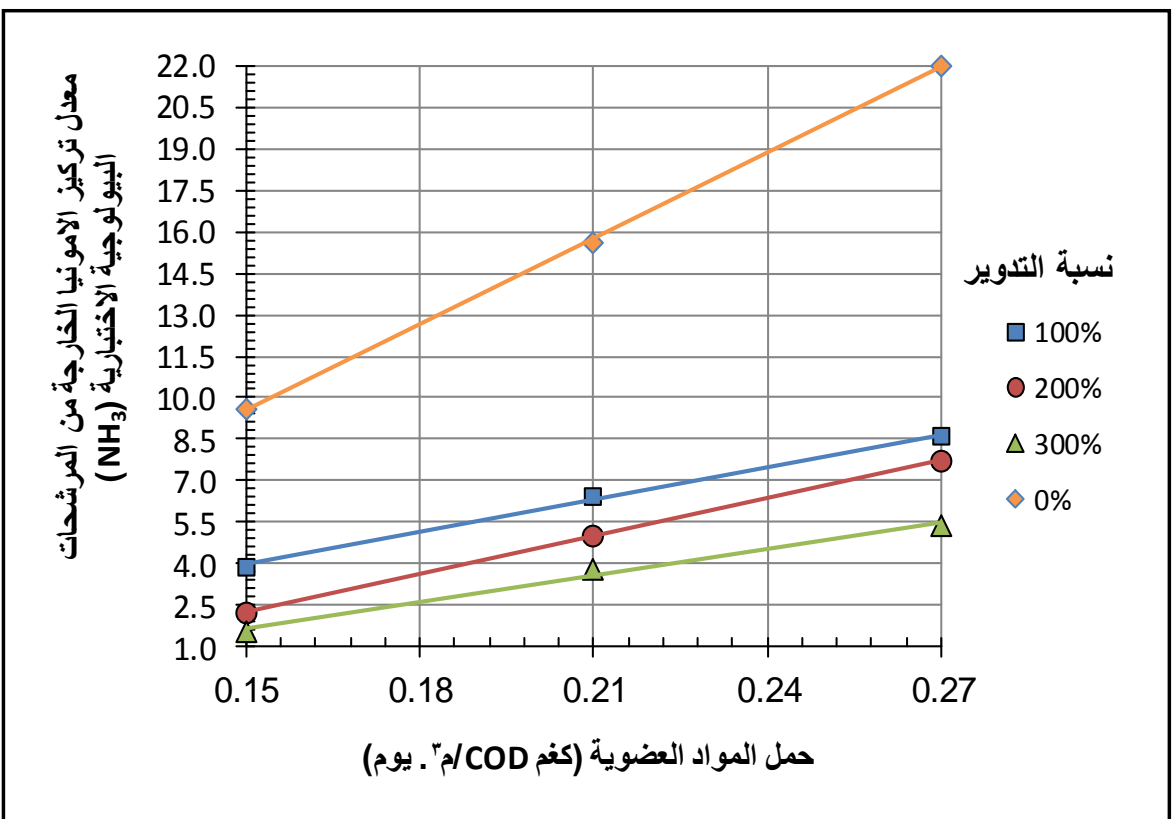

شكل (3) تأثير تغير حمل المواد العضوية في معدل تركيز المواد العضوية الذائبة

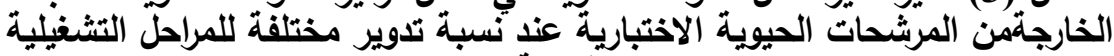

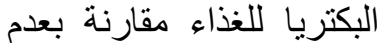

وجود عملية التدوير، فضاعلا

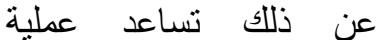
التدوير على إحداث تحسين لخصائص مياه الفضلات الداخلة للمنظومة وتزيد فرصة تماس المادة الغذائية مع الأحياء المجهرية من المادة الثنائ خلال تدوير المياه و إدخالها مرات عدة الى المرشح، كما وليا أنه بزيادة نسبة التدوير تزداد التردياد

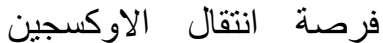
المذاب اللى داخل طبقة الأحياء المجهرية وهذا ما لإناء يزيد من فعالية الاحياء المجهرية الهو ائية الموجودة، ويتفق هذا التفسير مع مالية الئان أورده الباحثُون 
(Khan,etal; 2005) (Logan and Wagenseller, 2000)و و (Pal et al; 2010)

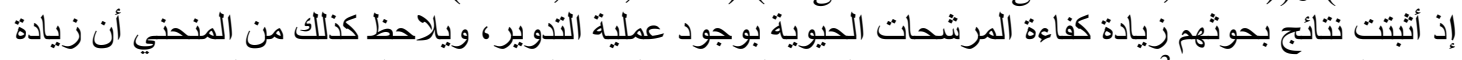

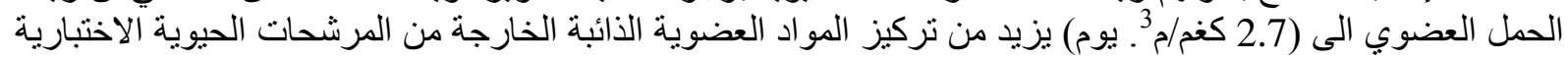
ذات نسب التدوير (300\%)، (200\%)، (100\%) و (150\%) الى حدود (135.3)، (154.3)، (169.6) و و(188.6) ملغم/

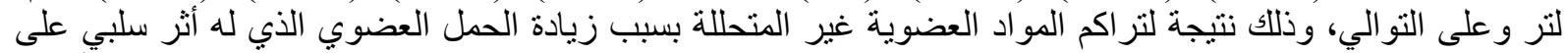

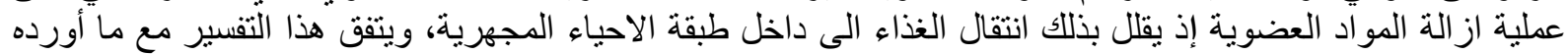

الباحث (Akker et al; 2011).

تأثير تغير حمل المواد العضوية ونسب التدوير في تركيز الامونيا في الماء الخارج

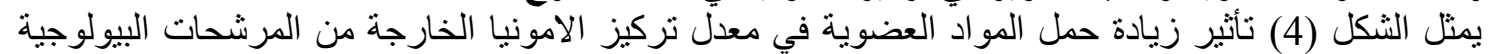

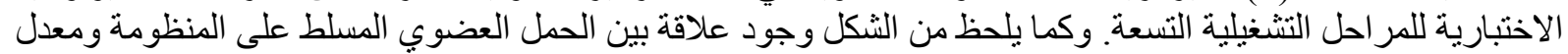

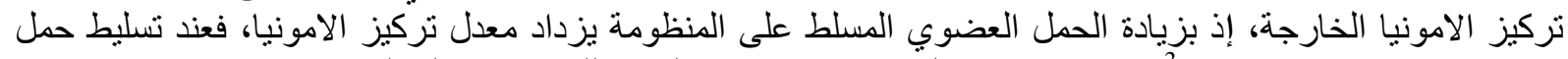

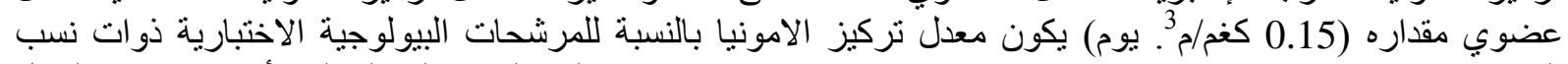

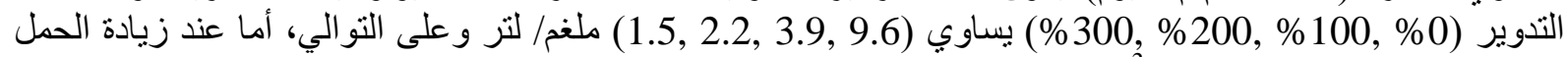

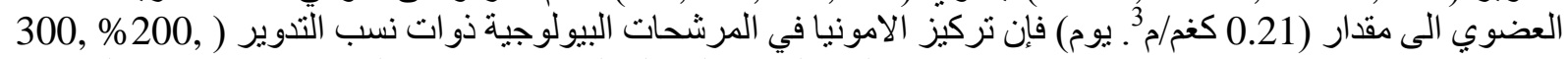

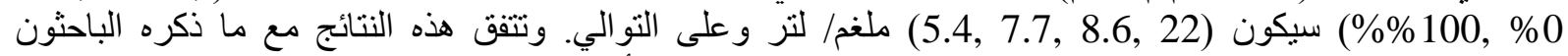

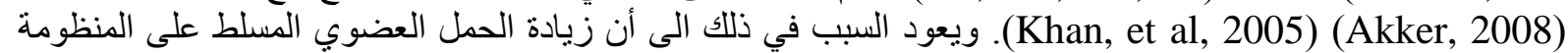

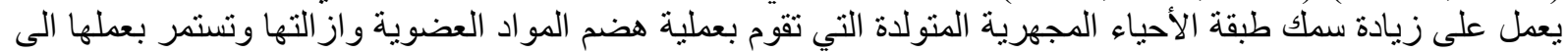

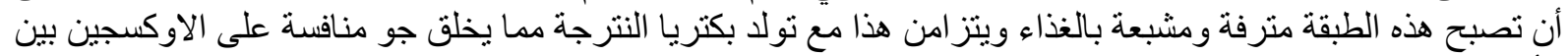

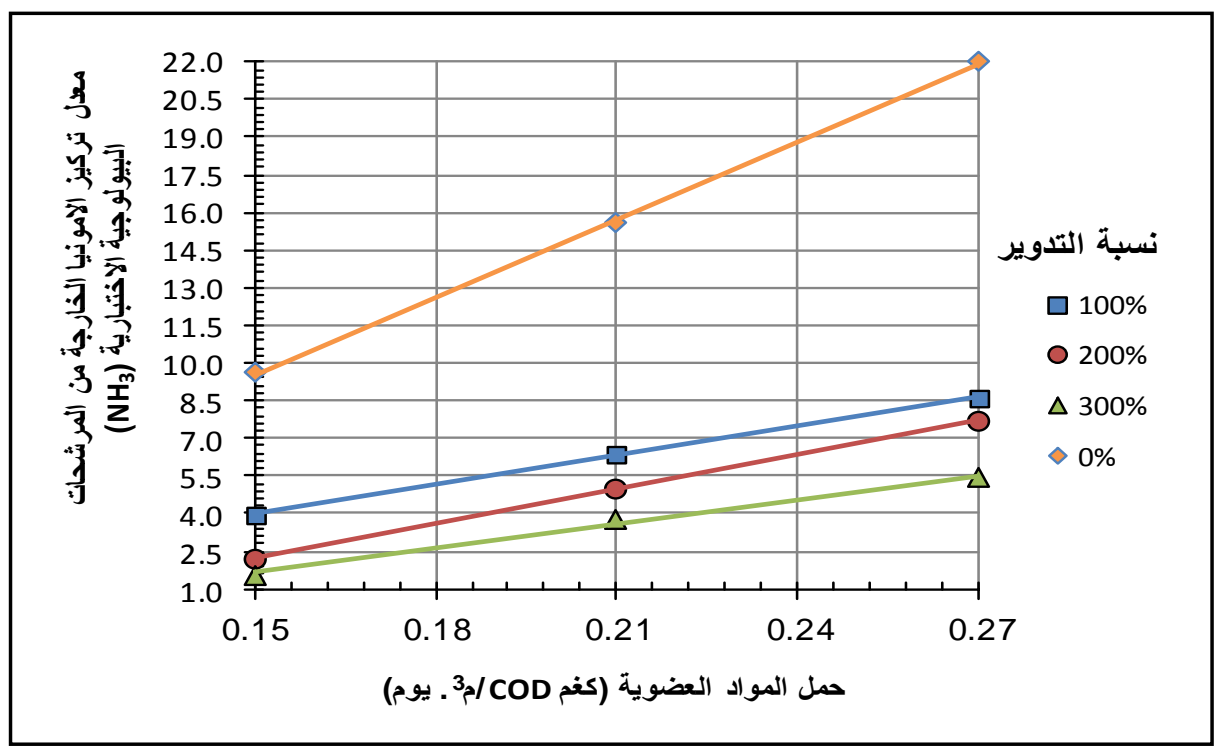

شكل (4) تأثير تغير حمل المواد العضوية في معدل تركيز الامونيا الخارجة من العندية

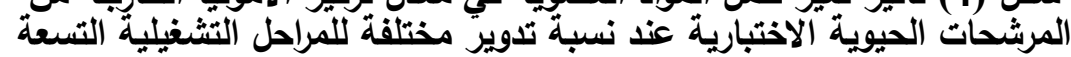

الأحياء المجهرية المتولدة الطئة (بكتريا ازياء الة الة المواد العضوية وبكتريا

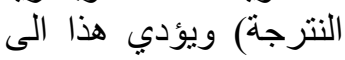

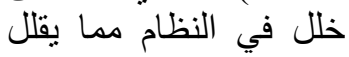
من عملية ازالة المواد

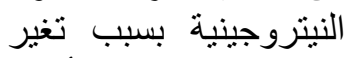
خصائص طبقة الأحياء المجهرية المتولدة داخل الاحلي المنظومة. ويتفق هذاء دال التفسير مع ما جاء باء به Akker et al, ) الباحثُون Bounds et ) (2008 '(al, 2010 Mofokeng, et al; ) Parker, ) (2009 Sadrnejad, ) $)$ (1986 .)(2011

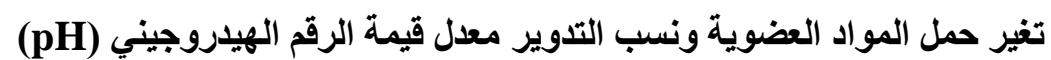

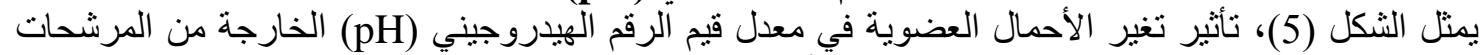

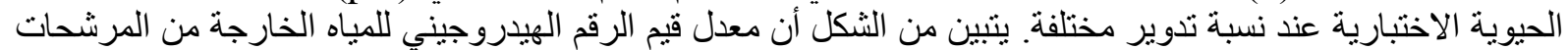

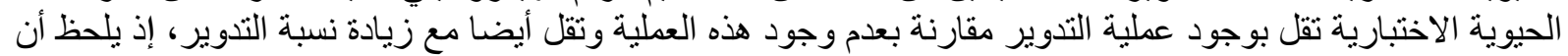

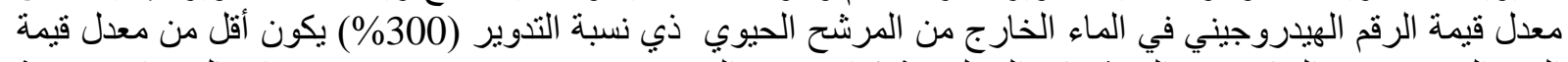

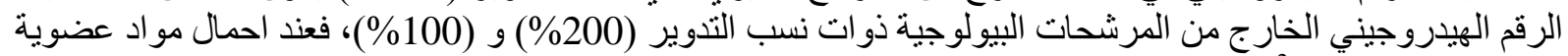

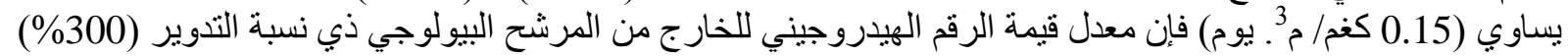

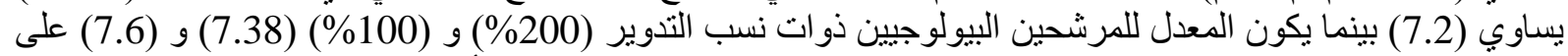

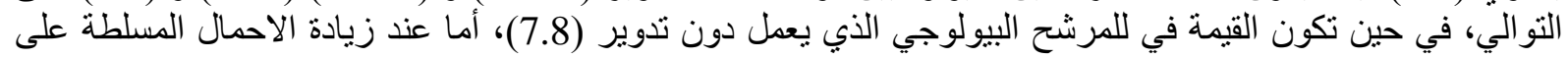




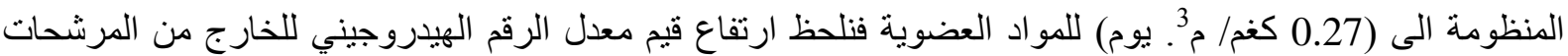

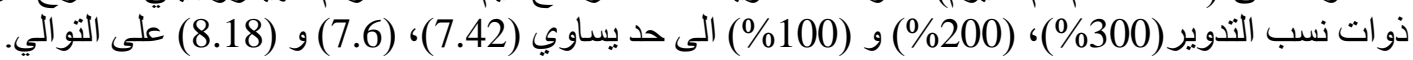

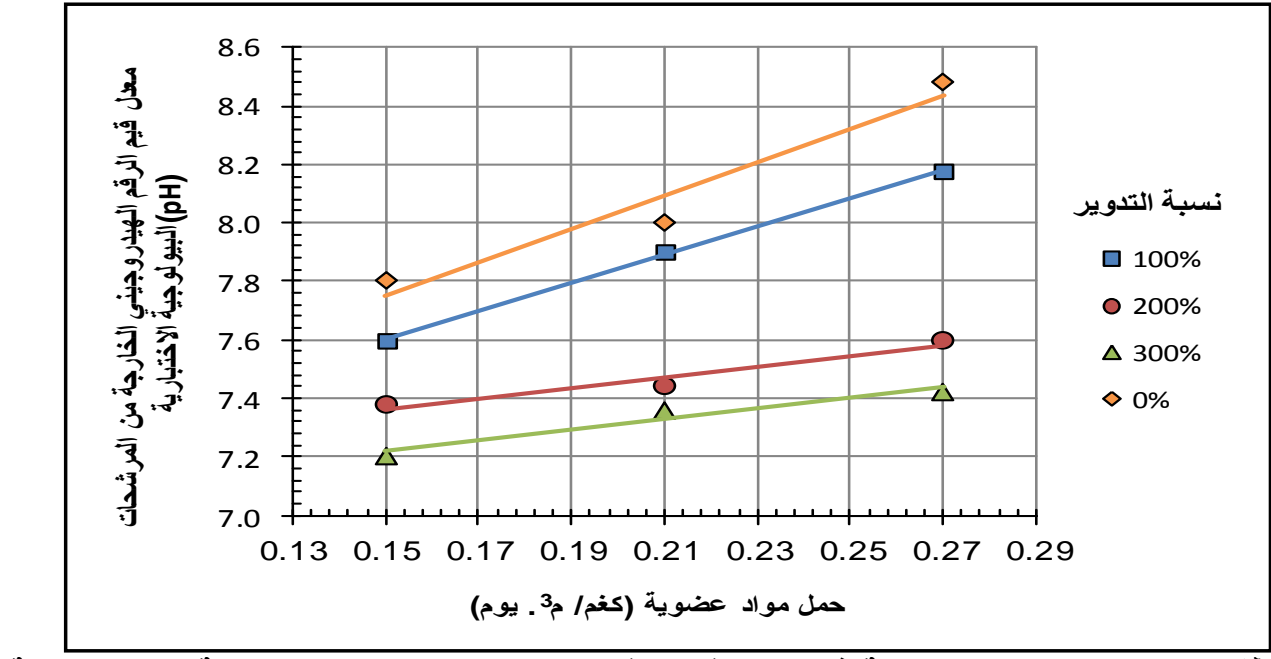

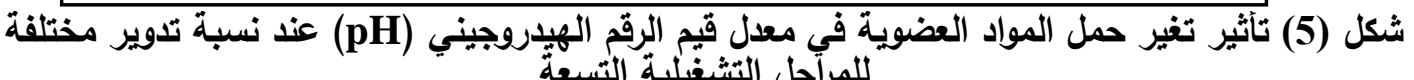

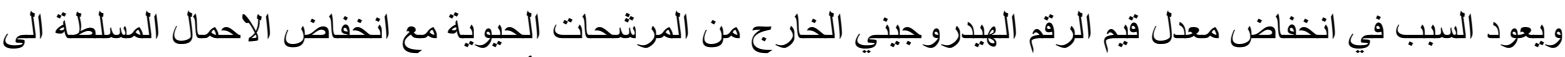

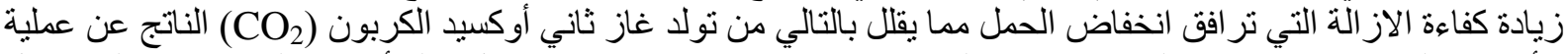

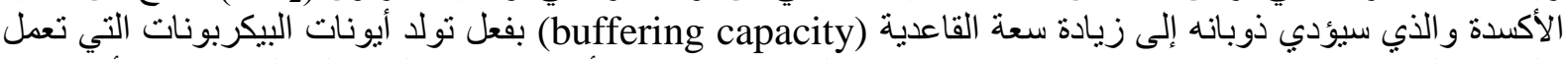
على معادلة قيم (pH) باتجاه حد مقداره (8.2) قاعدية البيكربونات سو اء ألئ أكانت طبيعة المياه الداخلة حامضية أم قاعدية

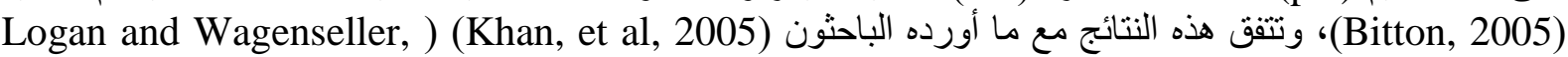

تأثير تغير حمل المواد الصلبة العالقة في تركيز المواد العضوية في الماء الخارج عند نسب تدوير مختلفة

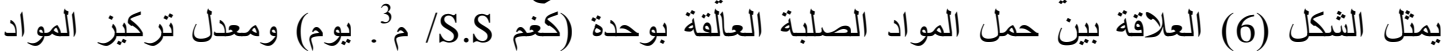

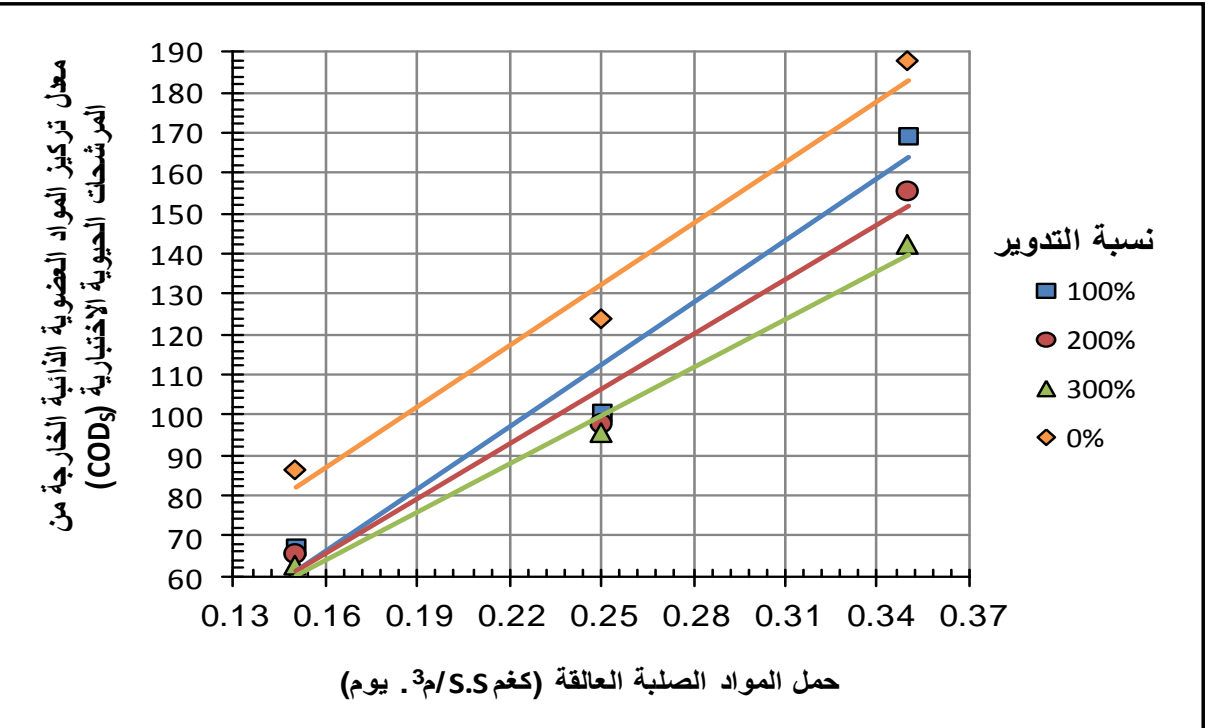

شكل (6): العلاقة بين حمل المواد الصلبة العالقة المسلطة على المرشحات الحيوية الاختبارية ومعدل تركيز المواد العضوية الذائبة (COD

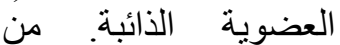
معاينة الثكل يتبين أنه بزيادة حمل المو اد الصلبة

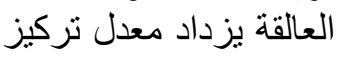

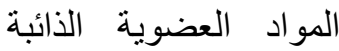
الخارجة من المرشحات العنة الحيوية الارية من الاختبارية الأربعة، كما يلحظ أن الن النية

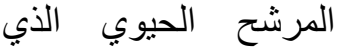

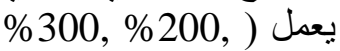

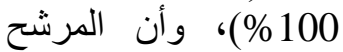
الحيوي ذي نسبة التدوير

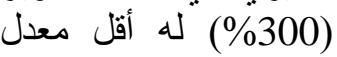

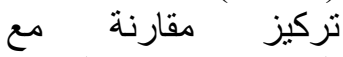

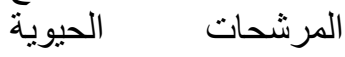
الاختبارية ذوات نسبة \%200, التدوير . \% 100

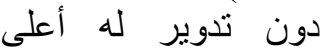
معدل تركيز مقارنة بباقي المرشحات الحيوية الاختبارية الثناثة ذو ات نسب التدوير 


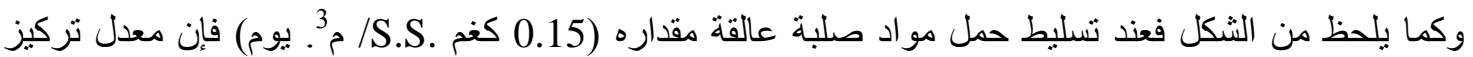

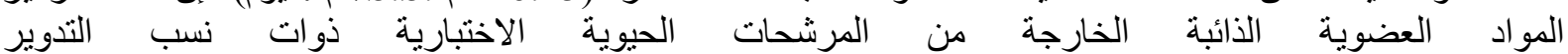

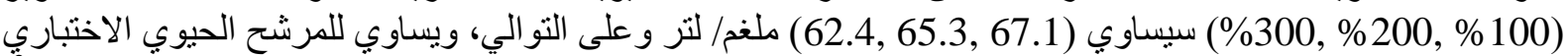

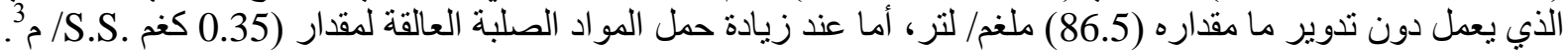

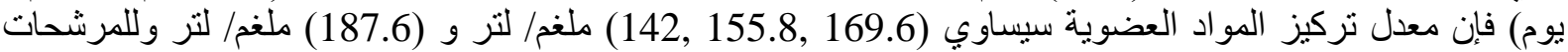

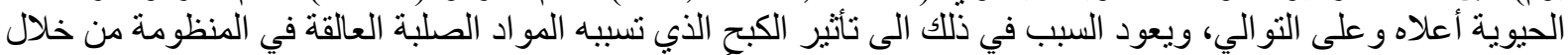

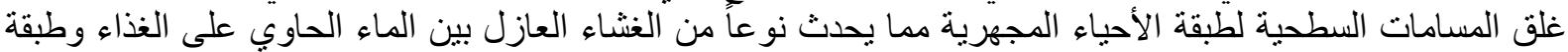

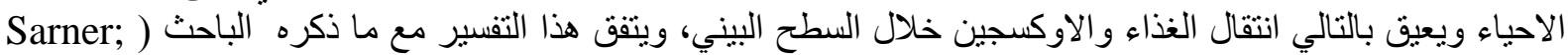

.(1981

1. تأثير تغير حمل المواد الصلبة العالقة في تركيز الامونيا في الماء الخارج عند نسب تدوير مختلفة

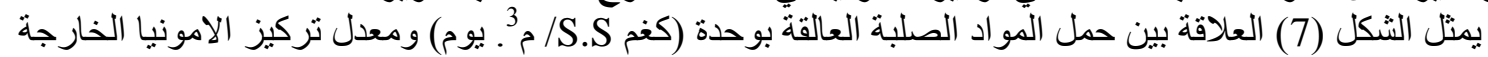

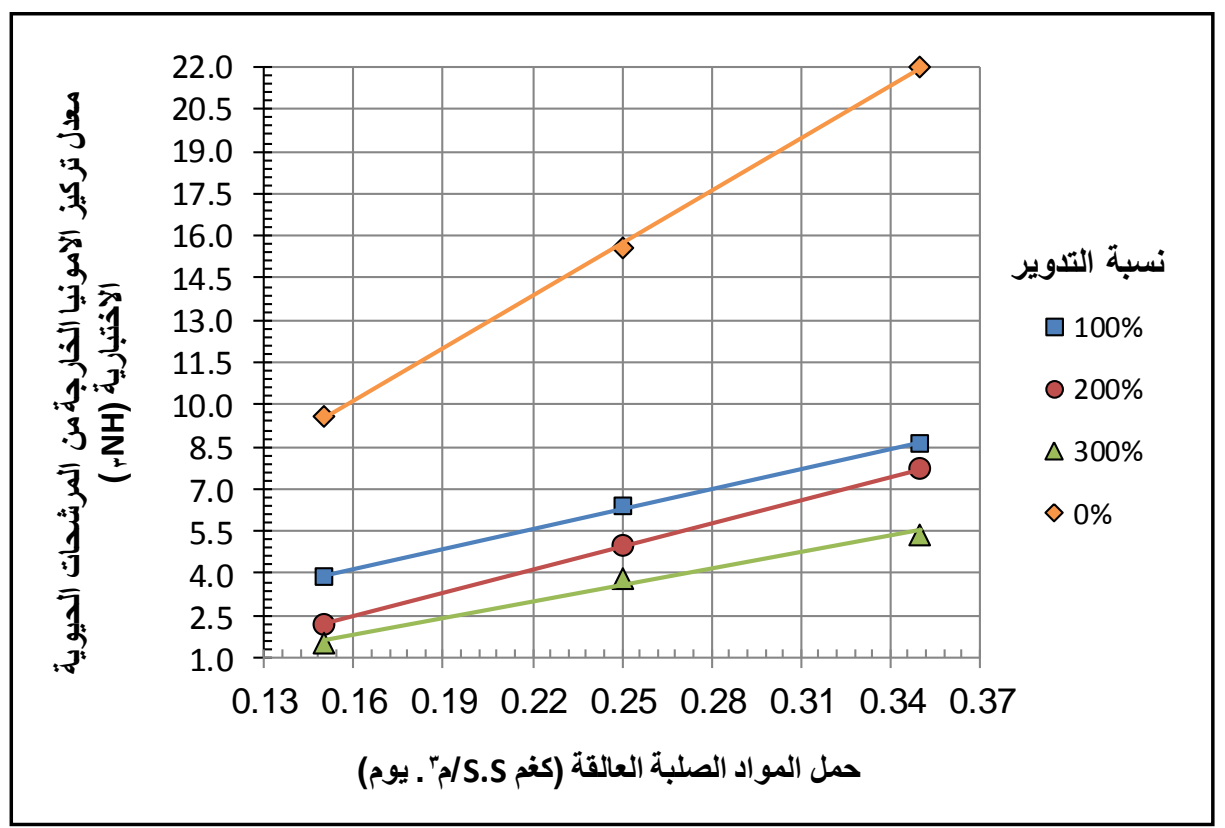

شكل (7) العلاقة بين حمل المواد الصلبة العالقة المسلطة على المرئلة الماتحات

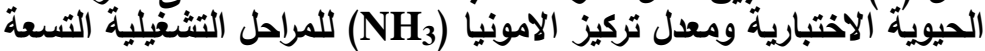

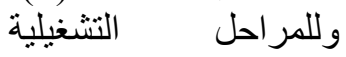
التسعة. وكما يلاحظ من لن لن الثنكل فان معدل تركيز الامونيا الخارجة من تركيز المرشحات الاختبارية الاربعة يزداد بزيادة حمل المو اد الصلبة العالقة، ويعود السبب في ذلك الى التأثير السلبي الذي تسبيه المواد العالقة على بكتريا النترجة من الني العال

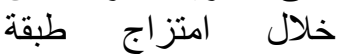
الاحياء المجهرية مع لإلية المواد الصلبة العالقة

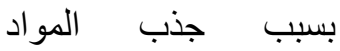
الصلبة العالقة لبكتريا النترجة فتصبح بذلك لكئل طبقة متمردة وغير محبة لإتمام عملها بصنة بصورة كاملة ( Akker et al, . (2008

تأثثر تغير حمل المواد الصلبة العالقة في تركيز الفوسفات في الماء الخارج عند نسب تدوير مختلفة

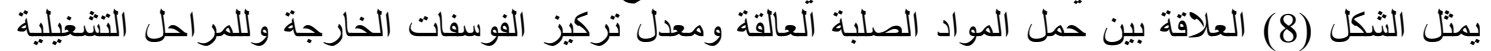

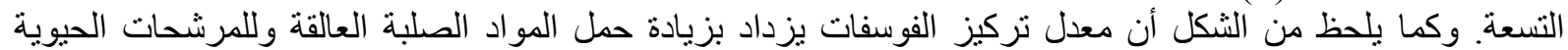

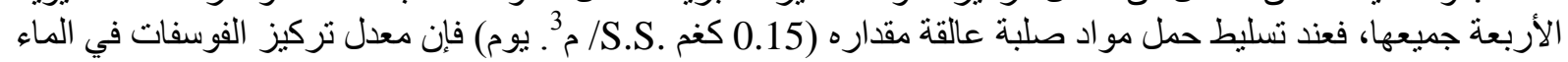

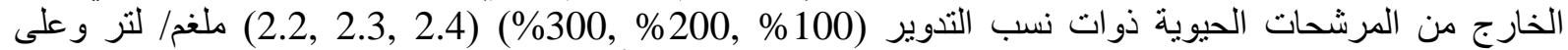

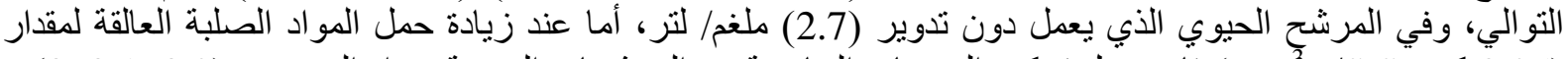

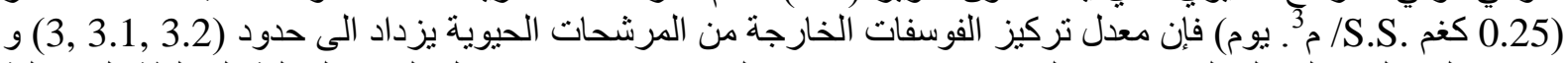

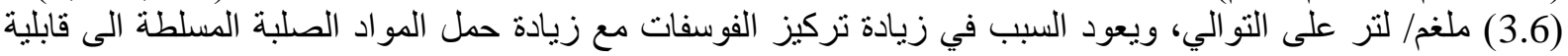

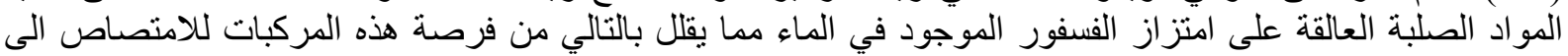

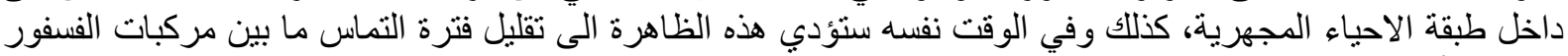

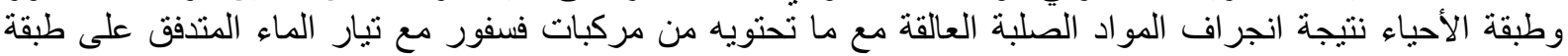

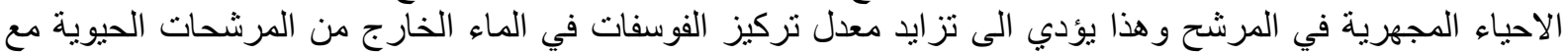

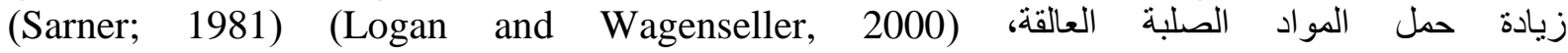




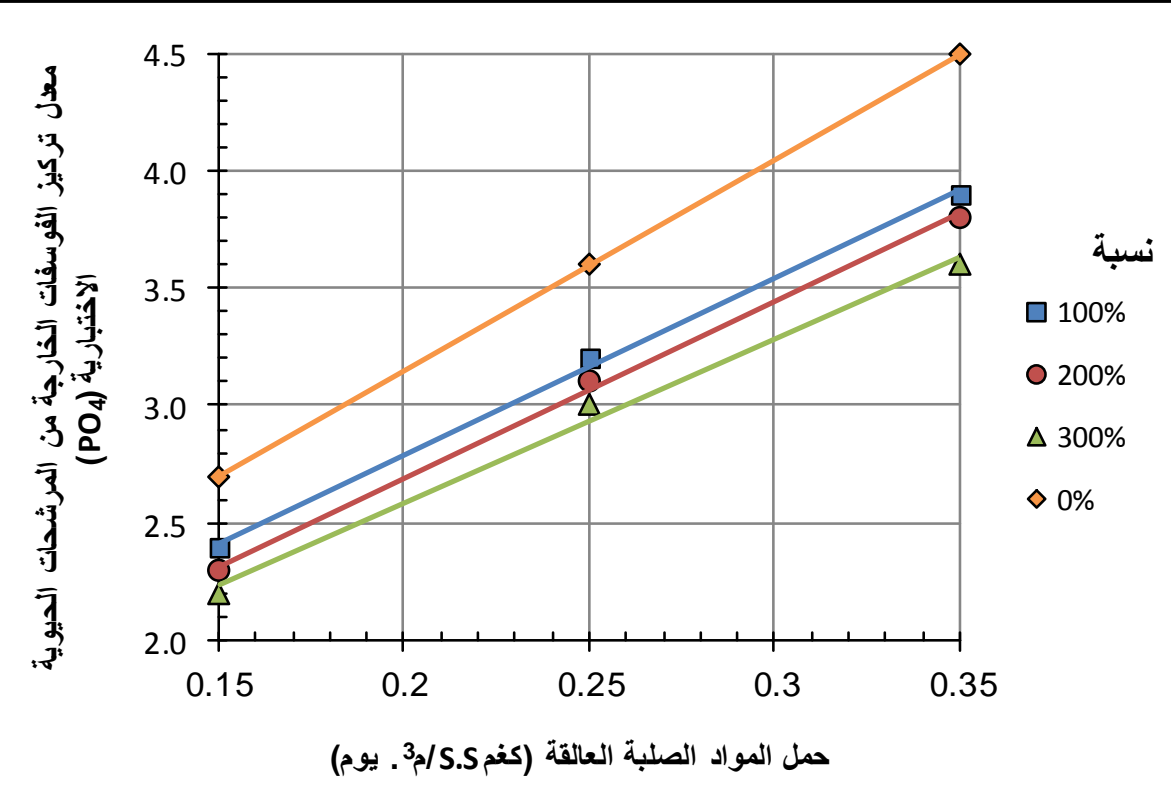

شكل (8) العلاقة بين حمل المواد الصلبة العالقة المسلطة على المرشحات الحيوية الاختبارية ومعدل تركيز الفوسفات (PO4)

1. استخدام عملية التدوير بنسب (100\%، 200\%، 300\%) ادى اللى زيادة كفاءة ازالة المرشحات البيولوجية

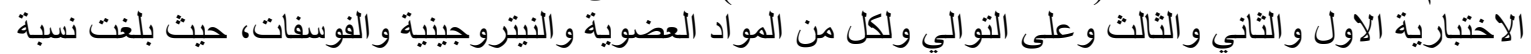

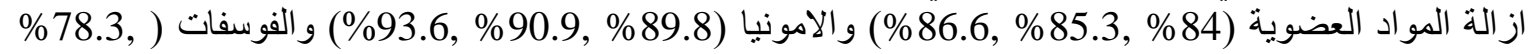

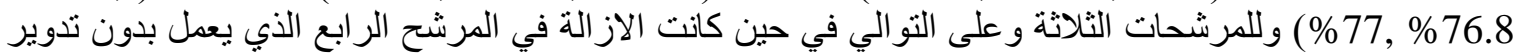

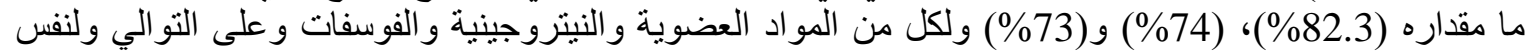

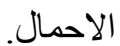

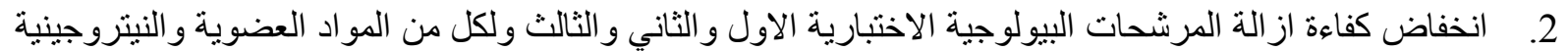

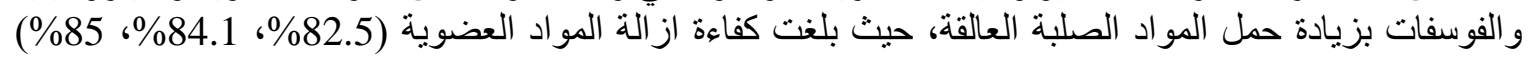

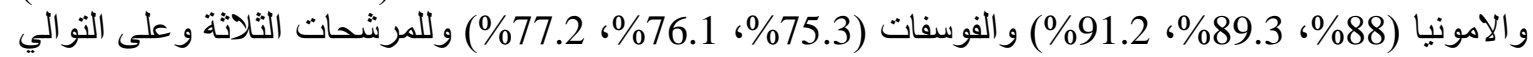

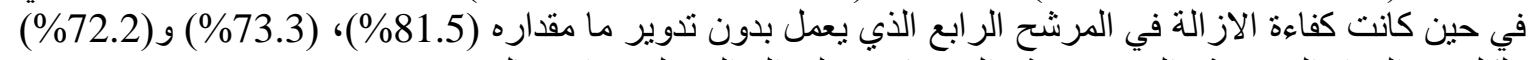

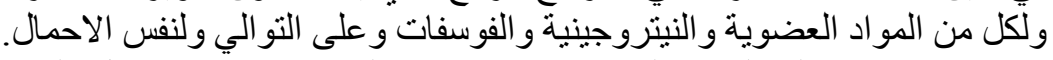

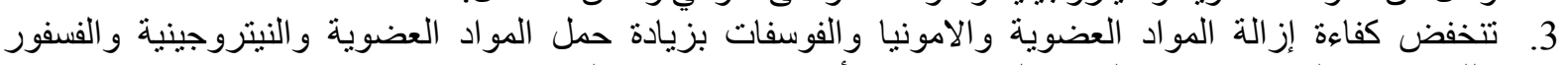

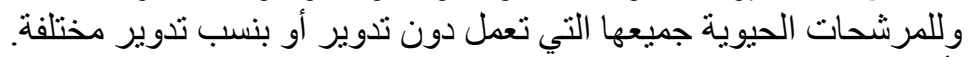

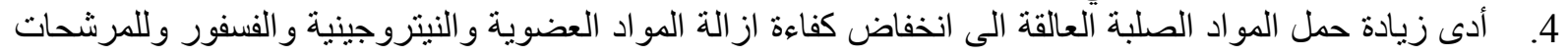
الحيوية الاربعة.

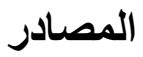

Akker B. V. D.; Holmes M.; Pearce P.; Cromar N. J. \& Field H. J. F. (2011), "Structure of nitrifying biofilms in a high-rate trickling filter" Journal of water Research, Vol. 45, pp. 3489-3498 .

Al-Ahmady Kossay K. and Al-Rahmani Nadeia A.; (2011) "Comparison Efficiency for Using the One and Two Stages Anaerobic Biological Filters in Treating Domestic Greywater, AlRafidain Engineering Journal, Vol. 19, No. 5.

Bitton G. (2005), "Wastewater microbiology" Third Edition, University of Florida, Ch. 8. 
Bounds J.; Ye J.; Kulick F. M. and Boltz J. P. (2010), "Nitrifying trickling filter provides reliable, low-energy, and cost-effective tertiary municipal wastewater treatment of a lagoon effluent" Water Environment Federation, email: jianchang.ye@brentw.com.

Brown and Caldwell (1979), "Fixed growth reactions, west point pilot plant study, volume III." Rep. prepared for the Municipality of Metropolitan Seattle, Walnut Creek, Calif. .

Hammer, M. J.; Wiley J. \& Sons (1986), "Water and wastewater technology" New York, pp. 536 .

Karrufa S. N. (1985), "A study of some variables effect on the biological fluidized bed treatment of wastewater" Thesis Master of Science In Civil Engineering (Environment), Mosul University .

Khan A. R.; Min K. S.; Mumtaz \& Marwat G. A. (2005), "Effluent recirculation in slag media trickling filter for enhanced organic and nitrogen removal" Journal chemistry Soc. Pak, Vol. 27, No. 4 .

Logan B. E.; Wagenseller G. A. (2000), "Molecular size distribution of dissolved organic matter in wastewater transformed by treatment in a full-scale trickling filter" Water Environment Research, Vol. 72, No. 3 .

Magallón L. M. P. (2008), "Trickling filter efficiency in BOD removal" email: lperez@dtdep.com.

Maheesan P. M.; Srinikethan G.; Harikumar, P. S., (2011), "Performance evaluation of integrated treatment plant of trickling filter and construct wetland" The international Journal of Engineering Science and Technology (IJEST), Vol. 3, No.1, pp. 305-307.

McGhee T. J. \& Steel E. W., (1991) "Water supply \& Sewerage" $6^{\text {th }}$ edition, McGraw Hill, publishing company, New York.

Metcalf and eddy, Inc., (2003), "Wastewater engineering treatment/disposal/reuse" fourth edition, McGraw-Hill, inc, New York, Ch. 7 .

Morton A. E. 1. T.; Auvermann B. ph. D., (2001), "Comparison of plastic trickling filter media for the treatment of swine lagoon effluent" An ASAE Meeting Presentation, paper No.: 012286, July 30-August 1 .

Mofokeng T. Muller A. Wentzel M. Ekama G. (2009) "Full-scale trials of external nitrification on plastic media nitrifying trickling filter" Water Research Group, Department of Civil Engineering, University of Cape Town, Private Bag X3, Rondebosch 7701, South Africa. Pal S.; Sarkar U.; Dasgupta D., (2010), "Dynamic simulation of secondary treatment processes using trickling filters in a sewage treatment works in Howrah, West Bengal, India" Desalination, Vol. 253, P. 135-140 .

Parker D. S. (1986), "Nitrification in trickling filters" Journal of water pollution control federation, Vol. 58, No. 9 .

Sadrnejad S. A., (2011), "Nitrification processes in Tehran wastewater treatment plant" International Scholarly Research Network ISRN Mechanical Engineering, Vol. 20, Article ID 545794, 9 pages.

Sarner E., (1981) "Removal of dissolved and particulate organic matter in high-rate trickling filters" Journal of water research, Vo. 15, pp. 671-678 .

Tsanis I. K.; Prescott K. L. \& Shen H., (1998), "Modelling of phosphorus and suspended solids in Cootes Paradise marsh" Elsevier Science, Vol. 114, pp. 1-17 .

Vanrolleghem P. A.; Nopens I. and Capalozza C., (2001), "Stability analysis of a synthetic municipal wastewater" Department Of Applied Mathematics, Biometrics and Process Control, Technical report, pp. 1-22.

تم اجراء البحث في كلية ألهندسة = جامعة ألموصل 